\title{
Risk of Dementia Associated with Elevated Plasma Homocysteine in a Latin American Population
}

\author{
Inara J. Chacón, ${ }^{1,2}$ Aldrín E. Molero, ${ }^{3,4}$ Gloria Pino-Ramírez, ${ }^{5}$ José A. Luchsinger, , 6, 7,8 \\ Joseph H. Lee, ${ }^{1,6,8}$ and Gladys E. Maestre ${ }^{1,3}$ \\ ${ }^{1}$ Gertrude H. Sergievsky Center, Columbia University, New York, NY, USA \\ ${ }^{2}$ Unit of Medical Genetics, University of Zulia, Maracaibo, Venezuela \\ ${ }^{3}$ Neurosciences Laboratory, Institute for Biological Research, University of Zulia, Maracaibo, Venezuela \\ ${ }^{4}$ Department of Neurology, Albert Einstein College of Medicine, Bronx, New York, NY 10461, USA \\ ${ }^{5}$ Center for Psychological Research, Universidad Rafael Urdaneta, Maracaibo, Venezuela \\ ${ }^{6}$ Taub Institute for Research of Alzheimer's Disease and the Aging Brain, Columbia University, New York, NY, USA \\ ${ }^{7}$ Division of General Medicine, Department of Medicine, Columbia University College of Physicians and Surgeons, \\ New York, NY, USA \\ ${ }^{8}$ Department of Epidemiology, School of Public Health, Columbia University, New York, NY, USA
}

Correspondence should be addressed to Gladys E. Maestre, gem6@columbia.edu

Received 26 March 2009; Revised 16 June 2009; Accepted 22 July 2009

Recommended by Vincenzo Solfrizzi

The relationship between total homocysteine (tHcy) and dementia risk remains controversial, as the association varies among populations and dementia subtypes. We studied a Venezuelan population that has high prevalence of both elevated tHcy and dementia. We tested the hypotheses that (1) elevated tHcy is associated with increased dementia risk, (2) the risk is greater for vascular dementia $(\mathrm{VaD})$ than for Alzheimer's disease (AD), and (3) a history of stroke may partly explain this association. 2100 participants ( $\geq 55$ years old) of the Maracaibo Aging Study underwent standardized neurological, neuropsychiatric, and cardiovascular assessments. Elevated tHcy was significantly associated with dementia, primarily VaD. When history of stroke and other confounding factors were taken into account, elevated tHcy remained a significant risk factor in older ( $>66$ years), but not in younger (55-66 years) subjects. Ongoing studies of this population may provide insight into the mechanism by which tHcy increases risk for dementia.

Copyright (C) 2009 Inara J. Chacón et al. This is an open access article distributed under the Creative Commons Attribution License, which permits unrestricted use, distribution, and reproduction in any medium, provided the original work is properly cited.

\section{Introduction}

Hyperhomocysteinemia has been linked to a number of pathological changes in the endothelium and small vessels [1-6]. Oxidized metabolites of homocysteine have been associated with intraneuronal accumulation of amyloid$\beta$ (A $\beta$ ) 42 and neurotoxicity $[7,8]$. These changes have been proposed as the underlying mechanism explaining epidemiological observations that moderate elevation of total plasma homocysteine (tHcy) is associated with an increased risk of cardiovascular and cerebrovascular disease [9] and dementia $[10,11]$. However, the relationship between tHcy and dementia is complex, because tHcy levels vary with sex and age [12-14] and are influenced by diet (including folate intake), lifestyle, health status, history of medication, and genetic factors [12, 15-18]. Risk of dementia increases with age and is influenced by many of the same factors [19]. The interaction of these multiple variables makes it difficult to discriminate the independent contribution of tHcy to dementia risk. Moreover, because most previous studies examined subjects who were 65 years of age or older $[10,20-22]$, those studies lacked a sufficiently broad age range necessary to distinguish the effects of age from that of elevated tHcy. In addition, most research examining tHcy as a risk factor for dementia has been carried out in developed countries [10, 23-27]; few studies have addressed this issue in populations of Hispanic descent residing in the developing world, particularly in Latin America, where 
dietary supplementation with folate and multivitamins is uncommon $[28,29]$.

In the current study, we examined the association between tHcy level and risk of dementia in an elderly population residing in the Caribbean city of Maracaibo, Venezuela. This population offers an opportunity to evaluate the association between tHcy level and dementia risk, because it has a high prevalence of dementia [30], mean tHcy levels that are substantially higher than those in the U.S. or Europe [14], and limited dietary and medical interventions to prevent or treat hyperhomocysteinemia [28, 31]. In addition, the study participants included individuals 55 years of age and older, providing information about tHcy as a risk factor for dementia in an age range that has not been well studied. Specifically, the present study tested the hypotheses that (1) high tHcy is related to increased risk of dementia; (2) the risk is greater for vascular dementia (VaD) than for Alzheimer's disease (AD), and (3) a history of stroke, representing a major cerebrovascular disease event, may be part of the pathway explaining this association.

\section{Materials and Methods}

2.1. Participants and Setting. Subjects were participants in the Maracaibo Aging Study (MAS), a population-based cohort study that is investigating age-related diseases among 2437 elderly residents of the community of Santa Lucia, Maracaibo, Venezuela [32]. The present study includes only baseline cross-sectional data for the 2100 subjects that had tHcy measurements. Sex and age distributions, educational level, frequency of traditional cardiovascular risk factors (CVRFs), and prevalence of dementia did not differ significantly between the evaluated group and the 337 subjects without tHcy measurements (data not shown). Information on hypercholesterolemia, diabetes, smoking status, hypertension, and stroke was not available for analysis in a small percentage of cases, due to the facts that reliable information could not be obtained, that some subjects did not respond to certain questions, or that some assays failed. However, the proportion of individuals with missing values was not significantly different among demented or nondemented participants. The University of Zulia Institutional Ethical Review Board approved the MAS, and informed consent was obtained from all participants.

2.2. Clinical Evaluation. The clinical evaluation included a full battery of neuropsychiatric examinations that integrated medical and family history with history of risk factors for dementia. Standardized cardiovascular evaluation, nutritional assessment, and neuropsychological testing were also performed for every participant. For participants with dementia, information concerning risk factors was obtained from family informants. Methods are described in detail elsewhere [30]. A diagnosis of dementia was determined by consensus in a diagnostic conference of physicians, psychologists, and social workers, based on the criteria in the Diagnostic and Statistical Manual of Mental Disorders (4th edition) [33]. AD was diagnosed following the criteria of the NINCDS/ADRDA [34]. The criteria of the State of California Alzheimer's Disease Diagnostic and Treatment Centers (ADDTC) [35] were used for diagnosis of $\mathrm{VaD}$. The ADDTC criteria require evidence of two or more ischemic strokes (at least one infarct outside the cerebellum) by history, neurological signs, and/or neuroimaging studies (CT or T1-weighted MRI), or a single stroke with an evident temporal relationship between the stroke and onset of dementia. In the absence of a defined stroke, clinical and neuroimaging evidence for Binswanger's disease is sufficient to make the diagnosis of possible $\mathrm{VaD}$. History of stroke was taken from self-reports, which defined stroke as an acute neurological deficit lasting more than 24 hours that required medical assistance.

2.3. Laboratory Analyses. Plasma tHcy, vitamin B12, and folate were measured using blood samples obtained between 7:00 and 8:00 AM, after overnight fasting. All blood samples were obtained and processed at the Cardiovascular Center of the University of Zulia (CCUZ) in Maracaibo. Samples were immediately placed in crushed ice and protected from light and were processed within one hour of collection. The biochemical assays for all samples were performed at the CCUZ. As a quality control measure, a subset of samples ( $n=40)$ was tested at the University of Texas Southwestern Medical School, using a method based on that of Araki and Sako [36]. Apolipoprotein E(APOE) was genotyped using a modified version [37] of the technique described by Hixson and Vernier [38] . Details of sample collection and analyses have been previously published [14].

2.4. Statistical Analysis. Means for demographic characteristics were compared using $t$-tests, and differences in the distribution of cardiovascular risk factors between groups (e.g., demented versus nondemented) were evaluated using the Pearson $\chi^{2}$ test. Levels of tHcy, vitamin B12, and folate were log-transformed to fit normal distributions. Odds ratios (ORs) and 95\% confidence intervals (CI) were calculated using two logistic regression models. Model 1 adjusted for age, sex, education, diabetes, folate, vitamin B12, and APOE genotype. Model 2 adjusted for a history of stroke, in addition to all of the covariates in Model 1. The latter model was designed to assess whether stroke was an intermediate factor [39], that is, a factor in the pathway in the relationship between tHcy and dementia [5, 9, 40]. Therefore, Model 2 was intended to determine if the association between tHcy and dementia was partly mediated by stroke [41].

We conducted analyses relating tHcy level to the risk of dementia for the entire population, and also for two age groups differentiated using the median age of the entire sample (66 years) as the cut point. This was done to assess the effect of elevated tHcy on the risk of dementia in individuals between 55 and 66 years of age, since this age range is not usually studied. We also added an interaction term to the logistic regression model to evaluate a possible interaction between age group and tHcy. For this purpose, tHcy $\geq 14 \mu \mathrm{mol} / \mathrm{L}$ was used to define hyperhomocysteinemia [10]. 
TABle 1: Characteristics of the Maracaibo Aging Study population.

\begin{tabular}{|c|c|c|c|}
\hline Characteristics & All & Demented & Not demented \\
\hline Population, no. ( $\%$ females) & $2100(67.0)$ & $169(74.0)$ & $1931(66.4)$ \\
\hline Age, mean (SD), y & $67.2(9.0)$ & $77.8(8.6)^{* *}$ & $66.3(8.3)$ \\
\hline Illiteracy, $N(\%)$ & $298 / 2100(14.2)$ & $61 / 169(36.1)^{* *}$ & $237 / 1931(12.3)$ \\
\hline Education, mean (SD), y & $5.6(4.0)$ & $3.2(3.2)^{* *}$ & $5.8(4.0)$ \\
\hline Hypercholesterolemia, $N(\%)$ & $711 / 1553(45.8)$ & $49 / 121(40.5)$ & $662 / 1432(46.2)$ \\
\hline Diabetes, $N(\%)$ & 287/2099 (13.7) & $32 / 169(19.0)^{*}$ & $255 / 1930(13.2)$ \\
\hline Current smoker, $N(\%)$ & $350 / 2100(16.7)$ & $20 / 169(12.0)$ & $329 / 1931(17.0)$ \\
\hline Hypertension, $N(\%)$ & $1739 / 2100(82.8)$ & $141 / 169(83.4)$ & $1598 / 1931(82.8)$ \\
\hline Stroke, $N(\%)$ & $113 / 2099(5.4)$ & $40 / 169(23.7)^{* *}$ & $72 / 1930(3.7)$ \\
\hline Hyperhomocysteinemia, $N(\%)$ & $844 / 2100(40.2)$ & $117 / 169(69.2)^{*}$ & 727/1931 (37.6) \\
\hline $\mathrm{tHcy}$, mean $(\mathrm{SD}), \mathrm{mol} / \mathrm{L}$ & $14.2(6.3)$ & $18.6(7.5)^{*}$ & $13.9(6.0)$ \\
\hline Folate, mean (SD), (ng/ml) & $5.3(2.9)$ & $4.8(3.3)^{*}$ & $5.3(3.0)$ \\
\hline Vit B12, mean (SD), (pmol/ml) & $416.9(335.0)$ & $426.3(341.5)$ & $415.9(334.5)$ \\
\hline \multicolumn{4}{|l|}{ APOE allele frequency } \\
\hline ApoE- $\varepsilon 2$ & 0.046 & 0.035 & 0.047 \\
\hline ApoE- $\varepsilon 3$ & 0.838 & 0.769 & 0.842 \\
\hline ApoE-ع4 & 0.116 & $0.166^{*}$ & 0.111 \\
\hline
\end{tabular}

${ }^{*} P<.05 ;{ }^{*} P<.001$, between demented and not demented groups.

Finally, we evaluated tHcy as a risk factor for the principal forms of dementia, $\mathrm{AD}$ and $\mathrm{VaD}$. To do this, we used only $\mathrm{AD}$ or $\mathrm{VaD}$ cases and eliminated individuals suffering from other forms of dementia or from mixed $\mathrm{AD}$ and $\mathrm{VaD}$. All statistical analyses were performed using SPSS software, Version 12 (SPSS Inc., Chicago).

\section{Results}

3.1. Population Characteristics. Mean age of participants was 67.2 years (Table 1 ). The ratio of women to men was $2: 1$ for the entire study population. Men were slightly younger than women and had higher levels of education. Women were more likely to have hypercholesterolemia, and men were more likely to be current smokers. Hypertension, defined as systolic blood pressure $\geq 140 \mathrm{~mm} \mathrm{Hg}$ and diastolic pressure $\geq 90 \mathrm{~mm} \mathrm{Hg}$, was highly prevalent in this population, compared to published reports for other Hispanic populations: $84.0 \%$ in this study versus $66.4 \%$ in the Northern Manhattan Study [21]. The prevalence of self-reported stroke was 5.4\%. Frequency of the allele $\varepsilon 4$ of the Apolipoprotein E gene (ApoE- $\varepsilon 4$ ) was 12\% (Table 1).

3.2. Demented versus Nondemented Individuals. The overall prevalence of dementia was $8 \%$ (Table 1). Demented individuals were significantly older than nondemented individuals (77.8 versus 66.3 year, resp.), had fewer years of formal education (3.2 versus 5.8 years), lower folate levels ( 4.8 versus $5.3 \mathrm{ng} / \mathrm{mL}$ ), and higher tHcy levels ( 18.6 versus $13.9 \mu \mathrm{mol} / \mathrm{L}$, $P<.05$ in all cases) (Table 1). Prevalence of hypertension, current smoking, and hypercholesterolemia did not differ between demented and nondemented individuals; however, the prevalence of diabetes (19.0 versus $12.6 \%)$ and of stroke $(23.7$ versus $3.7 \%)$ was significantly higher $(P<.01$ in both cases) in demented individuals than in nondemented individuals. Frequency of the ApoE- $\varepsilon 4$ allele was significantly higher in demented individuals $(16.6$ versus $11.1 \%, P<.01$ ).

3.3. Homocysteine, Stroke, and Risk of Dementia. The overall prevalence of hyperhomocysteinemia ( $\mathrm{tHcy} \geq 14 \mu \mathrm{mol} / \mathrm{L}$ ) was high $(40.2 \%)$ in this cohort (Table 1$)$. Demented individuals were twice as likely as nondemented individuals to have hyperhomocysteinemia (69.4 versus $37.6 \%, \chi^{2}=64.9$, $P<.0001)$.

When all subjects were examined together, each unit increase in log-transformed tHcy level corresponded to a fourfold increase in the risk for dementia after adjustments for age, sex, education, diabetes, folate, vitamin B12, and APOE genotype (Table 2, Model 1). Adjustment for stroke history (Model 2) had little effect on the odds ratio (OR) for the total study population.

When the sample was stratified into two age groups, the unadjusted ORs for dementia associated with tHcy were similar for individuals 55-66 years and for individuals $>66$ years (Table 2). When adjusted for age, sex, education, diabetes, APOE genotype, folate, and vitamin B12 (Model 1), the ORs remained significant for both age groups, but the OR for the younger group was slightly higher than that for the older group (6.3 versus 4.2 ).

Stroke was strongly associated with dementia in both age groups (unadjusted $\mathrm{OR}=11.6,95 \%$ C.I. $=4.5-29.7$ for the younger group; $\mathrm{OR}=7.3,95 \%$ C.I. $=4.3-12.3$ for the older group, $P<.001$ ), even after adjustment for sex, age, education, diabetes, APOE genotype, folate, vitamin B12, and tHcy $(\mathrm{OR}=22.5$., $95 \%$ C.I. $=6.0-84.4$ for the younger group; $\mathrm{OR}=7.5,95 \%$ C.I. $=4.0-14.0$ for the older group). When adjusted for stroke, the OR for dementia associated with tHcy was relatively constant for individuals 
TABLE 2: Odds ratios (ORs) for risk of dementia associated with log-transformed levels of total homocysteine (tHcy).

\begin{tabular}{|c|c|c|c|c|c|c|c|c|c|c|}
\hline \multirow[b]{2}{*}{ Group } & \multirow[b]{2}{*}{ Risk factor } & \multirow{2}{*}{$\frac{\text { Number }}{\text { Cases/Total }}$} & \multicolumn{2}{|c|}{ Crude } & \multirow{2}{*}{$\frac{\text { Number }}{\text { Cases/Total }}$} & \multicolumn{2}{|c|}{ Model $1^{\mathrm{a}}$} & \multirow{2}{*}{$\frac{\text { Number }}{\text { Cases/Total }}$} & \multicolumn{2}{|c|}{ Model $2^{\mathrm{b}}$} \\
\hline & & & OR & $95 \% \mathrm{CI}$ & & OR & $95 \% \mathrm{CI}$ & & OR & $95 \% \mathrm{CI}$ \\
\hline Total sample & $\log (\mathrm{tHcy})$ & $169 / 2100$ & $6.3^{* *}$ & $4.2-9.3$ & $152 / 1787$ & $4.2^{* *}$ & $2.4-7.3$ & $152 / 1786$ & $3.6^{* *}$ & $2.0-6.4$ \\
\hline 55-66 years & $\log (\mathrm{tHcy})$ & $23 / 1094$ & $4.6^{*}$ & $1.7-12.3$ & $21 / 927$ & $6.3^{*}$ & $1.6-24.6$ & $21 / 927$ & 4.5 & $0.9-20.5$ \\
\hline$>66$ years & $\log (\mathrm{tHcy})$ & $146 / 1006$ & $4.7^{* *}$ & $2.9-7.5$ & $131 / 860$ & $4.2^{* *}$ & $2.3-7.8$ & $131 / 859$ & $3.8^{* *}$ & $2.0-7.2$ \\
\hline
\end{tabular}

${ }^{a}$ Model 1 adjusted for age, sex, education, diabetes, APOE genotype, folate, and vitamin B12; ${ }^{b}$ Model 2 adjusted for age, sex, education, diabetes, APOE genotype, folate, vitamin $\mathrm{B} 12$, and stroke, ${ }^{*} P \leq .02$; ${ }^{*} P<.001$.

TABle 3: Comparison of risk associated with total homocysteine (tHcy) for Alzheimer's disease (AD) and vascular dementia (VaD).

\begin{tabular}{|c|c|c|c|c|c|c|c|}
\hline \multirow[b]{2}{*}{ Group } & \multirow[b]{2}{*}{ Risk factor } & \multirow{2}{*}{$\begin{array}{c}\text { No. } \\
\text { Cases/Total }\end{array}$} & \multicolumn{2}{|c|}{ Crude } & \multirow{2}{*}{$\begin{array}{c}\text { No. } \\
\text { Cases/Total }\end{array}$} & \multicolumn{2}{|c|}{ Adjusted $^{\mathrm{a}}$} \\
\hline & & & OR & $95 \%$ CI & & OR & $95 \% \mathrm{CI}$ \\
\hline $\mathrm{AD}$ & $\log (\mathrm{tHcy})$ & $74 / 2005$ & $4.3^{*}$ & $2.5-7.5$ & 65/1701 & 1.9 & $0.9-4.2$ \\
\hline $\mathrm{VaD}$ & $\log (\mathrm{tHcy})$ & $48 / 1979$ & $7.8^{*}$ & $4.1-15.1$ & $45 / 1681$ & $4.6^{*}$ & $2.0-11.1$ \\
\hline
\end{tabular}

${ }^{a}$ Adjusted model includes age, sex, education, diabetes, folate, vitamin B12, and APOE genotype; ${ }^{*} P \leq .001$, criteria from the NINCDS/ADRDA [34] were used to diagnose $\mathrm{AD}$ and criteria from the ADDTC [35] to diagnose VaD.

$>66$ years (Table 2, Model 2). However, the OR for the younger group was reduced two folds and was no longer statistically significant, suggesting that stroke is acting as a mediator between elevated tHcy and dementia.

For the total study population, 74 cases of dementia were clinically classified as $\mathrm{AD}$, and 48 as $\mathrm{VaD}$. After adjusting for covariates, elevated tHcy was a significant risk factor for $\mathrm{VaD}$, but not for $\mathrm{AD}$ (Table 3).

\section{Discussion}

Hyperhomocysteinemia is a significant risk factor for dementia in the Maracaibo Aging Study population. Elevated tHcy was associated with a fourfold increase in dementia risk in both younger and older age groups, and the magnitude of risk was even higher in younger than in older subjects. Thus, the relationship between tHcy and dementia exists over a broad age range. However, our results suggest that a history of stroke mediates the relationship between tHcy and dementia, and that this effect may decline with age. When stroke history was considered (Table 2, Model 2), the magnitude of dementia risk associated with elevated tHcy was reduced in the younger group, but not in the older group. The reduced risk in the younger group suggests that elevated tHcy may influence the risk of dementia by increasing the risk of cerebrovascular disease and strokerelated deficiencies, corroborating previous reports $[25,27$, 42]. In other words, stroke may be an intermediate factor [39] in the disease-causing pathway of tHcy. Alternatively, elevated tHcy and stroke may act as independent risk factors, with the influence of stroke overwhelmingly stronger than that of tHcy. To test this hypothesis, we will need to examine the temporality, which cannot be determined from the present cross-sectional study. Our ongoing longitudinal study of the MAS population will test this hypothesis.

In addition to disclosing age-related changes in the relationship between hyperhomocysteinemia and dementia, results of the present study showed that risk for $\mathrm{VaD}$ related to $\mathrm{tHcy}$ was much higher than risk for $\mathrm{AD}$ (Table 3), further supporting the role of cerebral vascular pathways $[1,4-$ $6,9,22]$. The relationship between hyperhomocysteinemia and $\mathrm{AD}$ is controversial $[10,27,43]$. Recent studies have suggested that tHcy is a marker of coexisting vascular conditions, rather than a direct risk factor for AD [44-46]. The overall role of elevated tHcy as a risk factor for stroke and dementia is still unclear. A trial of supplementation of vitamins B6 and B12 and folate showed no apparent benefit to the secondary prevention of stroke [47]. A clinical trial using the same supplements for participants $\geq 65$ years of age with $\mathrm{tHcy} \geq 13 \mu \mathrm{mol} / \mathrm{L}$ found lower tHcy levels in the treatment group after two years, but no differences in cognition [48]. However, meta-analysis of clinical trials suggested that longer treatment with folate is associated with improvement in stroke risk [49], and this needs to be explored in relation to dementia.

One limitation of our study is its cross-sectional nature, restricting our inferences about causality. Longitudinal data from the ongoing MAS will provide further insight into the mechanisms involved in the relationship between hyperhomocysteinemia and dementia. The inclusion of a younger cohort allowed us to examine the influence of tHcy in preclinical stages; however, as expected, the younger cohort had a relatively small number of dementia cases (23 out of 1094 participants), resulting in a large confidence interval. Therefore, the observed differences between age groups should be interpreted with caution. Finally, our clinical definition of stroke did not include data on "silent" cerebrovascular disease from brain imaging, so prevalence of cerebrovascular disease may have been underestimated.

To the best of our knowledge, the present study provides one of the first assessments of elevated tHcy as a risk factor for dementia for individuals of Hispanic descent living under the nutritional and environmental conditions of a developing country. The only other study in populations 
of Latin America published to date simply examined the correlation between tHcy level and MMSE value but did not diagnose subjects as demented or differentiate between different types of dementia [29]. The Maracaibo Aging Study is well suited to addressing some of the limitations observed in earlier reports on the relationship between tHcy and dementia. The MAS includes a large subject population of individuals with similar genetic background and lifestyle, and for the most part, unexposed to different forms of interventions and treatments. Thus, the relationship between tHcy and dementia in this population may be less affected by confounding factors. By studying a relatively homogeneous population, some of the inconsistencies of the earlier studies on heterogeneous populations are reduced. Earlier studies included diverse ethnic groups with varying environmental exposures: epidemiologic studies of Caucasian populations in the U.S. and Great Britain [10, 22], and a study of Hispanics residing in North America [24] did find a significant correlation between tHcy levels and dementia, while a study of a multiracial community in Manhattan [21] did not. In some cases, the association was attributed to vitamin deficiencies, rather than to effects of elevated tHcy [20]. In the current study of the MAS population, the association found with dementia was independent of folate and vitamin B12 levels.

\section{Conclusions}

The present study examined the association between elevated tHcy and dementia over a broader age range than most previous population-based studies. Although arbitrarily selected, the age cut point allowed evaluation of the association of tHcy and dementia in a significant number (1094) of relatively young individuals (55-66 years). Although longitudinal data are needed to assess causality, the demonstrated relationship between tHcy and dementia in the two age groups of this Latin American population provides new insight into the impact of hyperhomocysteinemia throughout life, and into the relevance of tHcy as a risk factor in populations from developing countries, where hyperhomocysteinemia is common.

\section{Acknowledgments}

The authors thank the participants and assessment team of the Maracaibo Aging Study. This work was supported by FONACIT G-97000726, 98002041, S1-2001001066 (Maestre), Funda Conciencia (Maestre), and NIH Training Grant 1D43 TW06221-03 (Chacon).

\section{References}

[1] S. C. Romerio, L. Linder, J. Nyfeler, et al., "Acute hyperhomocysteinemia decreases NO bioavailability in healthy adults," Atherosclerosis, vol. 176, no. 2, pp. 337-344, 2004.

[2] G. Topal, A. Brunet, E. Millanvoye, et al., "Homocysteine induces oxidative stress by uncoupling of no synthase activity through reduction of tetrahydrobiopterin," Free Radical Biology and Medicine, vol. 36, no. 12, pp. 1532-1541, 2004.
[3] G. N. Welch and J. Loscalzo, "Homocysteine and atherothrombosis," The New England Journal of Medicine, vol. 338, no. 15 , pp. 1042-1043, 1998.

[4] H. Chen, R. Fitzgerald, A. T. Brown, et al., "Identification of a homocysteine receptor in the peripheral endothelium and its role in proliferation," Journal of Vascular Surgery, vol. 41, no. 5, pp. 853-860, 2005.

[5] C. B. Wright, M. C. Paik, T. R. Brown, et al., "Total homocysteine is associated with white matter hyperintensity volume: the northern manhattan study," Stroke, vol. 36, pp. 1207-1211, 2005.

[6] B. Censori, T. Partziguian, O. Manara, and M. Poloni, "Plasma homocysteine and severe white matter disease," Neurological Sciences, vol. 28, no. 5, pp. 259-263, 2007.

[7] P. Görtz, A. Hoinkes, W. Fleischer, et al., "Implications for hyperhomocysteinemia: not homocysteine but its oxidized forms strongly inhibit neuronal network activity," Journal of the Neurological Sciences, vol. 218, no. 1-2, pp. 109-114, 2004.

[8] T. Hasegawa, W. Ukai, D.-G. Jo, et al., "Homocysteic acid induces intraneuronal accumulation of neurotoxic $\mathrm{A} \beta 42$ : implications for the pathogenesis of Alzheimer's disease," Journal of Neuroscience Research, vol. 80, no. 6, pp. 869-876, 2005.

[9] I. J. Perry, H. Refsum, R. W. Morris, S. B. Ebrahim, P. M. Ueland, and A. G. Shaper, "Prospective study of serum total homocysteine concentration and risk of stroke in middle-aged British men," The Lancet, vol. 346, no. 8987, pp. 1395-1398, 1995.

[10] S. Seshadri, A. Beiser, J. Selhub, et al., "Plasma homocysteine as a risk factor for dementia and Alzheimer's disease," The New England Journal of Medicine, vol. 346, no. 7, pp. 476-483, 2002.

[11] R. Obeid and W. Herrmann, "Mechanisms of homocysteine neurotoxicity in neurodegenerative diseases with special reference to dementia," FEBS Letters, vol. 580, no. 13, pp. 29943005, 2006.

[12] V. Ganji and M. R. Kafai, "Demographic, health, lifestyle, and blood vitamin determinants of serum total homocysteine concentrations in the third National Health and Nutrition Examination Survey, 1988-1994," The American Journal of Clinical Nutrition, vol. 77, no. 4, pp. 826-833, 2003.

[13] J. Selhub, P. F. Jacques, P. W. F. Wilson, D. Rush, and I. H. Rosenberg, "Vitamin status and intake as primary determinants of homocysteinemia in an elderly population," Journal of the American Medical Association, vol. 270, no. 22, pp. 2693-2698, 1993.

[14] A. E. Molero, C. C. Altimari, D. A. Duran, E. Garcia, G. Pino-Ramirez, and G. E. Maestre, "Total plasma homocysteine values among elderly subjects: findings from the maracaibo aging study," Clinical Biochemistry, vol. 39, no. 10, pp. 1007$1015,2006$.

[15] H. Refsum, E. Nurk, A. D. Smith, et al., "The Hordaland Homocysteine Study: a community-based study of homocysteine, its determinants, and associations with disease," Journal of Nutrition, vol. 136, no. 6, pp. 1731S-1740S, 2006.

[16] M. Baines, M.-B. Kredan, J. Usher, et al., "The association of homocysteine and its determinants MTHFR genotype, folate, vitamin $\mathrm{B}_{12}$ and vitamin $\mathrm{B}_{6}$ with bone mineral density in postmenopausal British women," Bone, vol. 40, no. 3, pp. 730736, 2007.

[17] P. Verhoef and L. C. P. G. M. de Groot, "Dietary determinants of plasma homocysteine concentrations," Seminars in Vascular Medicine, vol. 5, no. 2, pp. 110-123, 2005. 
[18] H. Gellekink, M. den Heijer, S. G. Heil, and H. J. Blom, "Genetic determinants of plasma total homocysteine," Seminars in Vascular Medicine, vol. 5, no. 2, pp. 98-109, 2005.

[19] C. Qiu, D. De Ronchi, and L. Fratiglioni, "The epidemiology of the dementias: an update," Current Opinion in Psychiatry, vol. 20, no. 4, pp. 380-385, 2007.

[20] D. M. Kado, A. S. Karlamangla, M.-H. Huang, et al., "Homocysteine versus the vitamins folate, $\mathrm{B}_{6}$, and $\mathrm{B}_{12}$ as predictors of cognitive function and decline in older high-functioning adults: MacArthur studies of successful aging," The American Journal of Medicine, vol. 118, no. 2, pp. 161-167, 2005.

[21] J. A. Luchsinger, M.-X. Tang, S. Shea, J. Miller, R. Green, and R. Mayeux, "Plasma homocysteine levels and risk of Alzheimer disease," Neurology, vol. 62, no. 11, pp. 1972-1976, 2004.

[22] S. P. McIlroy, K. B. Dynan, J. T. Lawson, C. C. Patterson, and A. P. Passmore, "Moderately elevated plasma homocysteine, methylenetetrahydrofolate reductase genotype, and risk for stroke, vascular dementia, and Alzheimer disease in Northern Ireland," Stroke, vol. 33, no. 10, pp. 2351-2356, 2002.

[23] G. Ravaglia, P. Forti, F. Maioli, et al., "Homocysteine and folate as risk factors for dementia and Alzheimer disease," American Journal of Clinical Nutrition, vol. 82, no. 3, pp. 636-643, 2005.

[24] M. N. Haan, J. W. Miller, A. E. Aiello, et al., "Homocysteine, $\mathrm{B}$ vitamins, and the incidence of dementia and cognitive impairment: results from the sacramento area Latino Study on Aging," American Journal of Clinical Nutrition, vol. 85, no. 2, pp. 511-517, 2007.

[25] P. Quadri, C. Fragiacomo, R. Pezzati, E. Zanda, M. Tettamanti, and U. Lucca, "Homocysteine and B vitamins in mild cognitive impairment and dementia," Clinical Chemistry and Laboratory Medicine, vol. 43, no. 10, pp. 1096-1100, 2005.

[26] K. Nägga, R. Rajani, E. Mårdh, K. Borch, S. Mårdh, and J. Marcusson, "Cobalamin, folate, methylmalonic acid, homocysteine, and gastritis markers in dementia," Dementia and Geriatric Cognitive Disorders, vol. 16, no. 4, pp. 269-275, 2003.

[27] E. Köseoglu and Y. Karaman, "Relations between homocysteine, folate and vitamin $\mathrm{B}_{12}$ in vascular dementia and in Alzheimer disease," Clinical Biochemistry, vol. 40, no. 12, pp. 859-863, 2007.

[28] I. Darnton-Hill, J. O. Mora, H. Weinstein, S. Wilbur, and P. R. Nalubola, "Iron and folate fortification in the americas to prevent and control micronutrient malnutrition: an analysis," Nutrition Reviews, vol. 57, no. 1, pp. 25-31, 1999.

[29] M. Tassino, T. F. Campos, and R. O. Guerra, "Homocysteine (Hcy) and cognitive performance in a population sample of elderly Brazilians," Archives of Gerontology and Geriatrics, vol. 48, no. 2, pp. 142-145, 2009.

[30] A. E. Molero, G. Pino-Ramírez, and G. E. Maestre, "High prevalence of dementia in a Caribbean population," Neuroepidemiology, vol. 29, no. 1-2, pp. 107-112, 2007.

[31] L. Meertens, N. Díaz, L. Solano, M. A. Baron, and A. Rodríguez, "Serum homocysteine, folate and vitamin $\mathrm{B}_{12}$ in Venezuelan elderly," Archivos Latinoamericanos de Nutricion, vol. 57, no. 1, 2007.

[32] G. E. Maestre, G. Pino-Ramírez, A. E. Molero, et al., "The Maracaibo Aging Study: population and methodological issues," Neuroepidemiology, vol. 21, no. 4, pp. 194-201, 2002.

[33] APA: Dsm-iv: Diagnostic and Statistical Manual of Mental Disorders, American Psychiatric Association, Washington, DC, USA, 4th edition, 1994.

[34] G. McKhann, D. Drachman, and M. Folstein, "Clinical diagnosis of Alzheimer's disease: report of the NINCDS-ADRDA work group under the auspices of Department of Health and Human Services Task Force on Alzheimer's disease," Neurology, vol. 34, no. 7, pp. 939-944, 1984.

[35] H. C. Chui, J. I. Victoroff, D. Margolin, W. Jagust, R. Shankle, and R. Katzman, "Criteria for the diagnosis of ischemic vascular dementia proposed by the State of California Alzheimer's Disease Diagnostic and Treatment Centers," Neurology, vol. 42, no. 3, pp. 473-480, 1992.

[36] A. Araki and Y. Sako, "Determination of free and total homocysteine in human plasma by high-performance liquid chromatography with fluorescence detection," Journal of Chromatography, vol. 422, pp. 43-52, 1987.

[37] G. Maestre, R. Ottman, Y. Stern, et al., "Apolipoprotein E and Alzheimer's disease: ethnic variation in genotypic risks," Annals of Neurology, vol. 37, no. 2, pp. 254-259, 1995.

[38] J. E. Hixson and D. T. Vernier, "Restriction isotyping of human apolipoprotein $\mathrm{E}$ by gene amplification and cleavage with HhaI," Journal of Lipid Research, vol. 31, no. 3, pp. 545-548, 1990.

[39] K. J. Rothman, Epidemiology: An Introduction, Oxford University Press, New York, NY, USA, 2002.

[40] A. G. Bostom, I. H. Rosenberg, H. Silbershatz, et al., "Nonfasting plasma total homocysteine levels and stroke incidence in elderly persons: the Framingham Study," Annals of Internal Medicine, vol. 131, no. 5, pp. 352-355, 1999.

[41] H. C. Kraemer, E. Stice, A. Kazdin, D. Offord, and D. Kupfer, "How do risk factors work together? Mediators, moderators, and independent, overlapping, and proxy risk factors," American Journal of Psychiatry, vol. 158, no. 6, pp. 848-856, 2001.

[42] S. Seshadri, P. A. Wolf, A. S. Beiser, et al., "Association of plasma total homocysteine levels with subclinical brain injury: cerebral volumes, white matter hyperintensity, and silent brain infarcts at volumetric magnetic resonance imaging in the Framingham Offspring Study," Archives of Neurology, vol. 65, no. 5, pp. 642-649, 2008.

[43] S. Ariogul, M. Cankurtaran, N. Dagli, M. Khalil, and B. Yavuz, "Vitamin $\mathrm{B}_{12}$, folate, homocysteine and dementia: are they really related?" Archives of Gerontology and Geriatrics, vol. 40, no. 2, pp. 139-146, 2005.

[44] T. Matsui, M. Nemoto, M. Maruyama, et al., "Plasma homocysteine and risk of coexisting silent brain infarction in Alzheimer's disease," Neurodegenerative Diseases, vol. 2, no. 6, pp. 299-304, 2006.

[45] J. W. Miller, R. Green, D. M. Mungas, B. R. Reed, and W. J. Jagust, "Homocysteine, vitamin $\mathrm{B}_{6}$, and vascular disease in $\mathrm{AD}$ patients," Neurology, vol. 58, no. 10, pp. 1471-1475, 2002.

[46] K. Nilsson, L. Gustafson, and B. Hultberg, "Plasma homocysteine is elevated in elderly patients with memory complaints and vascular disease," Dementia and Geriatric Cognitive Disorders, vol. 23, no. 5, pp. 321-326, 2007.

[47] J. F. Toole, M. R. Malinow, L. E. Chambless, et al., “ Lowering homocysteine in patients with ischemic stroke to prevent recurrent stroke, myocardial infarction, and death: the vitamin intervention for stroke prevention (VISP) randomized controlled trial," Journal of the American Medical Association, vol. 291, no. 5, pp. 565-575, 2004.

[48] J. A. McMahon, T. J. Green, C. M. Skeaff, R. G. Knight, J. I. Mann, and S. M. Williams, "A controlled trial of homocysteine lowering and cognitive performance," The New England Journal of Medicine, vol. 354, no. 26, pp. 2764-2772, 2006.

[49] X. Wang, X. Qin, H. Demirtas, et al., "Efficacy of folic acid supplementation in stroke prevention: a meta-analysis," The Lancet, vol. 369, no. 9576, pp. 1876-1882, 2007. 


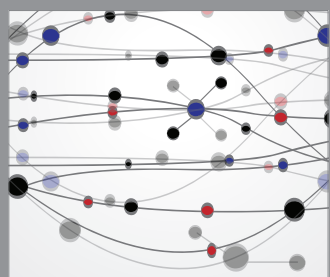

The Scientific World Journal
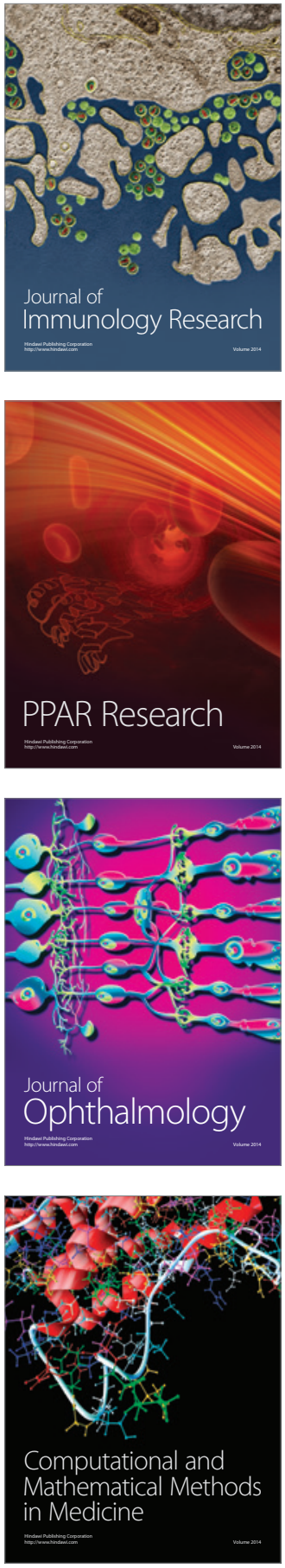

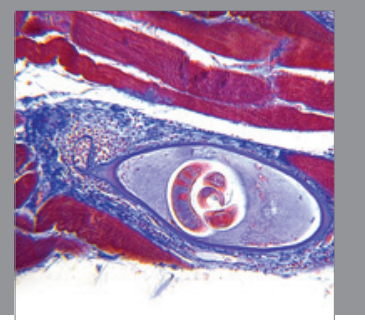

Gastroenterology

Research and Practice
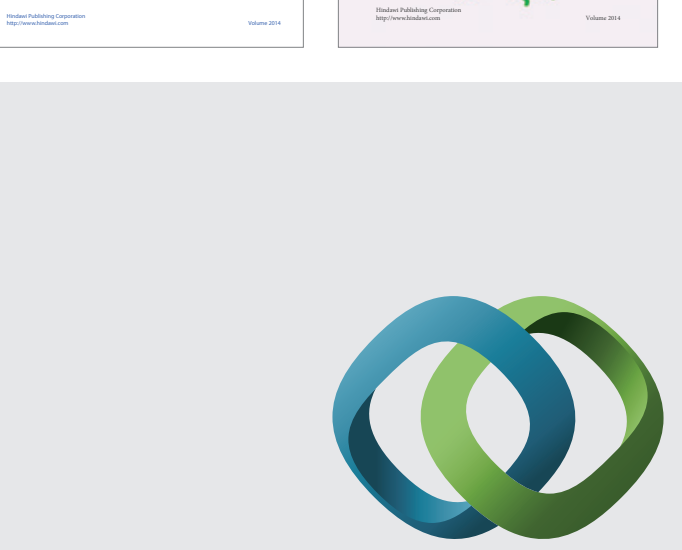

\section{Hindawi}

Submit your manuscripts at

http://www.hindawi.com
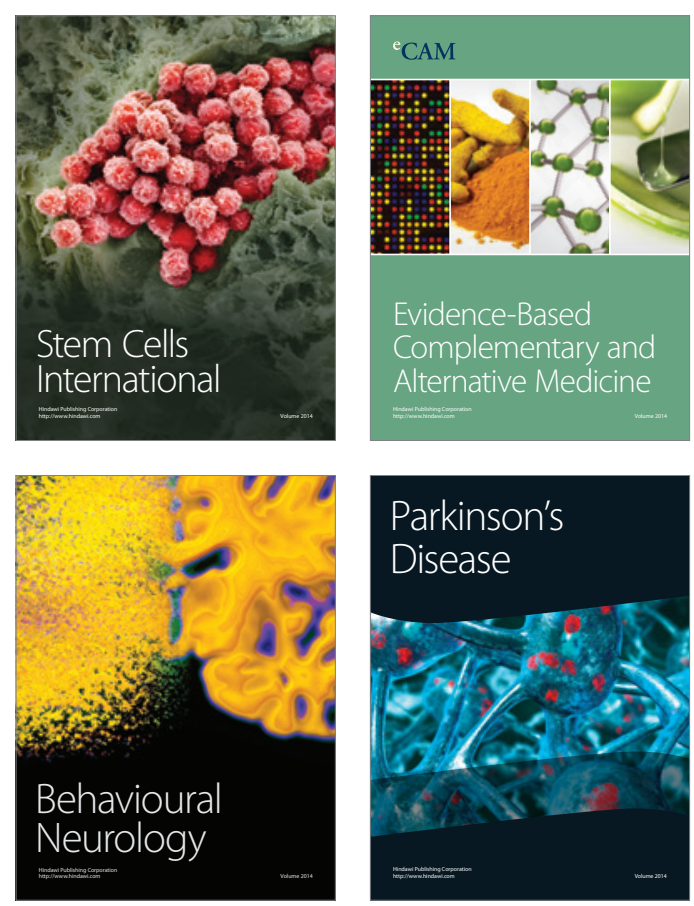

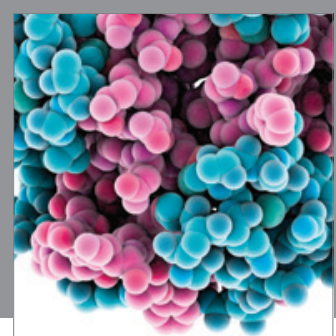

Journal of
Diabetes Research

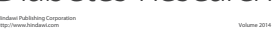

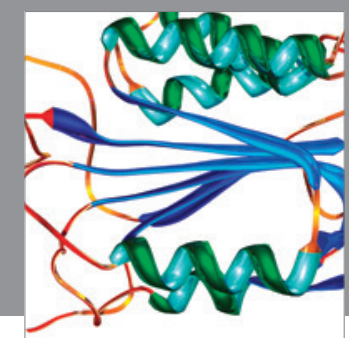

Disease Markers
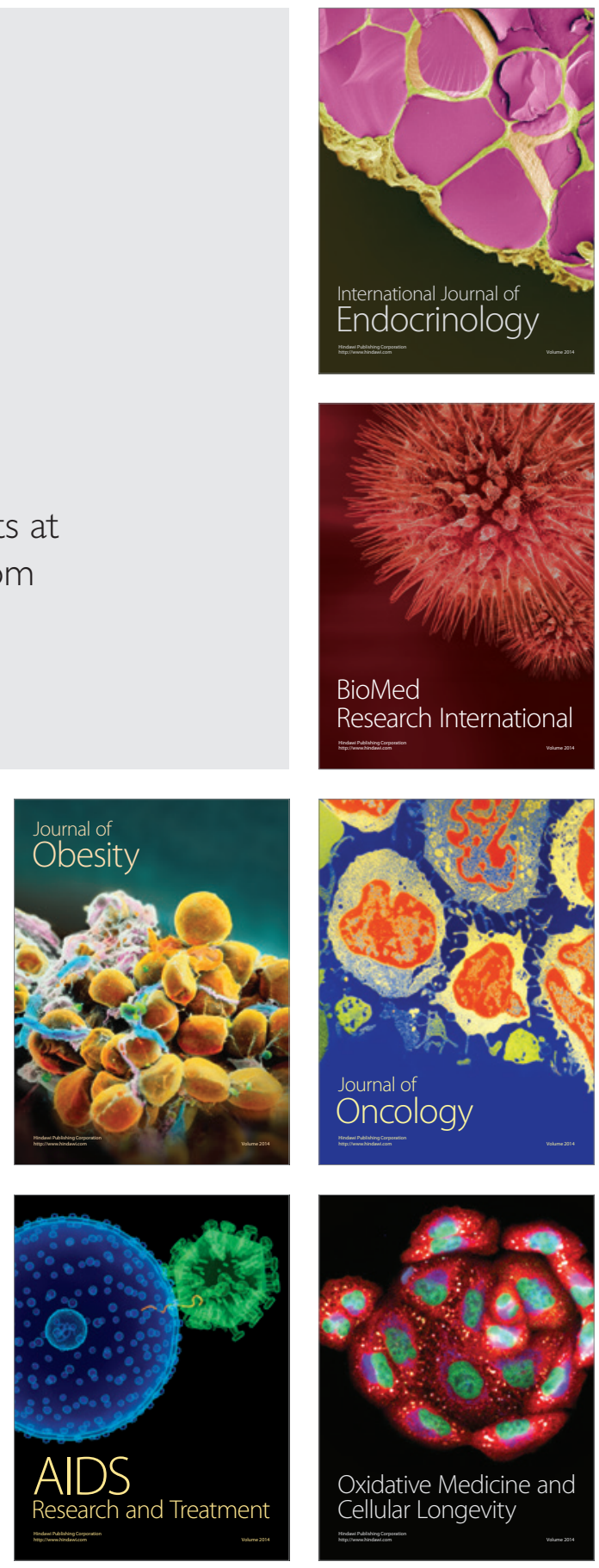